\title{
Acute sleep deprivation enhances susceptibility to the migraine substrate cortical spreading depolarization
}

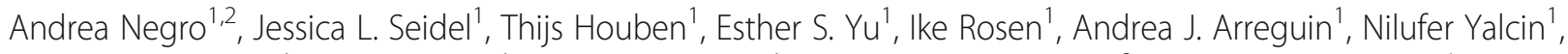
Lea Shorser-Gentile', Lea Pearlman', Homa Sadhegian', Ramalingam Vetrivelan ${ }^{3}$, Nancy L. Chamberlin ${ }^{4}$, Cenk Ayata ${ }^{1,5}$, Paolo Martelletti ${ }^{2}$, Michael A. Moskowitz ${ }^{6}$ and Katharina Eikermann-Haerter ${ }^{1,7^{*}}$ (D)

\begin{abstract}
Background: Migraine is a common headache disorder, with cortical spreading depolarization (CSD) considered as the underlying electrophysiological event. CSD is a slowly propagating wave of neuronal and glial depolarization. Sleep disorders are well known risk factors for migraine chronification, and changes in wake-sleep pattern such as sleep deprivation are common migraine triggers. The underlying mechanisms are unknown. As a step towards developing an animal model to study this, we test whether sleep deprivation, a modifiable migraine trigger, enhances CSD susceptibility in rodent models.

Methods: Acute sleep deprivation was achieved using the "gentle handling method", chosen to minimize stress and avoid confounding bias. Sleep deprivation was started with onset of light (diurnal lighting conditions), and assessment of CSD was performed at the end of a $6 \mathrm{~h}$ or $12 \mathrm{~h}$ sleep deprivation period. The effect of chronic sleep deprivation on CSD was assessed 6 weeks or 12 weeks after lesioning of the hypothalamic ventrolateral preoptic nucleus. All experiments were done in a blinded fashion with respect to sleep status. During 60 min of continuous topical $\mathrm{KCl}$ application, we assessed the total number of CSDs, the direct current shift amplitude and duration of the first CSD, the average and cumulative duration of all CSDs, propagation speed, and electrical CSD threshold.

Results: Acute sleep deprivation of $6 \mathrm{~h}(n=17)$ or $12 \mathrm{~h}(n=11)$ duration significantly increased CSD frequency compared to controls (17 \pm 4 and $18 \pm 2$, respectively, vs. $14 \pm 2$ CSDs/hour in controls; $p=0.003$ for both), whereas other electrophysiological properties of CSD were unchanged. Acute total sleep deprivation over $12 \mathrm{~h}$ but not over $6 \mathrm{~h}$ reduced the electrical threshold of CSD compared to controls ( $p=0.037$ and $p=0.095$, respectively). Chronic partial sleep deprivation in contrast did not affect CSD susceptibility in rats.

(Continued on next page)
\end{abstract}

\footnotetext{
* Correspondence: khaerter@mgh.harvard.edu

${ }^{1}$ Neurovascular Research Laboratory, Department of Radiology,

Massachusetts General Hospital, Harvard Medical School, Charlestown, MA, USA

7Department of Radiology, Massachusetts General Hospital, Harvard Medical School, 55 Fruit Street, Boston, MA 02114, USA

Full list of author information is available at the end of the article
} 
(Continued from previous page)

Conclusions: Acute but not chronic sleep deprivation enhances CSD susceptibility in rodents, possibly underlying its negative impact as a migraine trigger and exacerbating factor. Our findings underscore the importance of CSD as a therapeutic target in migraine and suggest that headache management should identify and treat associated sleep disorders.

Keywords: Cortical spreading depolarization, CSD, Migraine, Sleep deprivation, Ventrolateral preoptic (VLPO) nucleus, VLPO

\section{Introduction}

Migraine is a multifactorial neurovascular disorder characterized by recurrent episodes of headache. One third of patients experience transient neurological symptoms associated with their attacks, the so-called migraine aura. Migraine is among the most common neurological diseases, affecting approximately $20 \%$ of the adult population [1]. The socioeconomic impact is high [2, 3], and the World Health Organization recognized migraine as a major public health problem by ranking it as \#2 among all diseases causing disability [4] and as \#1 in under-50year-old humans of both genders [5]. Migraine attacks may increase in frequency over time, and approximately $2.5 \%$ of patients with episodic migraine develop chronic migraine [6]. The transition to more frequent attack patterns is influenced by genetic predisposition, co-morbid conditions, life events and lifestyle [7].

Sleep disorders are well known risk factors for migraine chronification $[7,8]$ and changes in wake-sleep patterns such as sleep deprivation are common migraine triggers [9]. Compared to a few decades ago, adults sleep less, and sleeping as little as possible is often seen as an admirable behavior. Sleep loss may result from total sleep deprivation (such as shift workers might experience), chronic sleep restriction (due to work, medical conditions or lifestyle), or sleep disruption (in sleep disorders such as sleep apnea or restless legs syndrome) [10]. Sleep disorders are frequently observed in specific headache diagnoses (e.g., migraine, tension-type headache, cluster headache) [11] and other nonspecific headache patterns (i.e., chronic daily headache, hypnic headache, "awakening" or morning headache) [12]. In migraineurs, sleep disorders are well known predictive factors of progression from episodic to chronic forms [13]. In contrast, a targeted behavioral sleep intervention can lead to an improvement in headache frequency and reversion from chronic to episodic migraine [14]. The sleep deprivationinduced increase in adenosine levels might be an underlying mechanism, because adenosine levels are elevated during migraine attacks, and administration of adenosine can precipitate migraine attacks [15].

Cortical spreading depolarization (CSD), discovered by Leão in 1944 [16], is considered the electrophysiological correlate of migraine aura, and a possible trigger of migraine headache [17]. CSD is an intense propagating depolarization of neuronal and glial membranes. Evoked when the local extracellular potassium concentration $\left[\mathrm{K}^{+}\right]_{\mathrm{e}}$ exceeds a critical threshold, CSD causes a loss of membrane resistance and massive ionic disturbances with cell swelling. Genetic and environmental factors important for the clinical manifestation of migraine have been shown to modulate cortical excitability, including the potential to elevate $\left[\mathrm{K}^{+}\right]_{\mathrm{e}}$ and glutamate to levels sufficient to initiate and facilitate CSD. For example, mutations causing the migraine-associated syndromes familial hemiplegic migraine (FHM) or cerebral autosomal dominant arteriopathy with subcortical infarcts and leukoencephalopathy (CADASIL) enhance CSD susceptibility $[18,19]$. Similarly, gonadal hormones modulate CSD susceptibility, to explain the female preponderance in migraine $[18,20]$. In the setting of sleep deprivation, adenosine overload with overstimulation of A1 receptors is a possible mechanism modulating neuronal activity and CSD, because adenosine $\mathrm{A}_{1}$ receptor activation contributes to the persistent secondary phase of Leão's cortical spreading depression [21, 22].

The current study found that acute sleep deprivation as a modifiable environmental factor enhances CSD susceptibility, possibly explaining its debilitating effects on migraine.

\section{Materials and methods \\ Experimental groups}

All experimental procedures were carried out in accordance with the Guide for Care and Use of Laboratory Animals (NIH Publication No. 85-23, 1996), and were approved by the institutional review board (MGH Subcommittee on Research Animal Care, SRAC) and Institutional Animal Use and Care Committee of Beth Israel Deaconess Medical Center. All animals were housed individually under controlled conditions $(12 \mathrm{~h}$ of light starting at 08:00) in an isolated ventilated chamber maintained at $20-22^{\circ} \mathrm{C}$ and given access to food and water ad libitum. Only male rodents were used in this study to reduce the number of animals needed to control for hormonal fluctuations during the female estrus cycle [23]. CSD recordings were carried out by an investigator blinded to the sleep deprivation status. 


\section{a) Acute Sleep Deprivation:}

A total of 58 rats (Sprague-Dawley, male, $340 \pm 40 \mathrm{~g}$; Charles River Laboratories, Wilmington, MA) were used to test the hypothesis that acute sleep deprivation enhances CSD susceptibility. Experimental groups consisted of 30 control rats as well as 11 rats after $12 \mathrm{~h}$ of sleep deprivation and 17 rats after $6 \mathrm{~h}$ of sleep deprivation. From the group of 30 control rats, we used 11 rats as controls interleaved with rats after $6 \mathrm{~h}$ of sleep deprivation and 19 rats as controls interleaved with rats after $12 \mathrm{~h}$ of sleep deprivation. Acute sleep deprivation was induced using the "gentle handling method" [24], chosen to minimize stress and avoid any confounding bias associated with enforced waking present with other techniques (e.g. lights, sounds, water tank). For the same reason, the "gentle handling method" was preferred over alternative techniques that use stimuli known to also serve as migraine triggers, e.g., stress, pain, light, smell or sound [25], which could have introduced additional confounding bias. Rats were kept awake by providing new objects into their home cage when they adopted a sleeping posture, i.e., curled up with eyes closed. Sleep deprivation was started with the onset of light cycle (diurnal lighting conditions, $8 \mathrm{am}-8 \mathrm{pm}$ ), and assessment of CSD was performed at the end of the $6 \mathrm{~h}$ or $12 \mathrm{~h}$ sleep deprivation period. Control rats were kept in the same environment but left undisturbed. Sleep-deprived rats and control rats were housed individually, in the same room. Every day, one control rat and one sleep-deprived rat were randomized and coded with the letter "A" or "B" on their cage card, by a person not involved in CSD recordings. The investigator performed 2 CSD recordings per day, testing 1 control rat and 1 sleepdeprived rat, in random order. The investigator pulled a card with " $\mathrm{A}$ " or "B" before CSD recordings, and started CSD recordings with the respective rat accordingly, not knowing the rat's sleep deprivation status.

\section{b) Chronic sleep deprivation}

A total of 29 rats (Sprague-Dawley, male, $405 \pm 30$ g; Taconic, Germantown, NY) were used to test the effect of partial chronic sleep deprivation on CSD susceptibility. To minimize stress and avoid any confounding bias associated with enforced waking, chronic sleep deprivation was induced by cytotoxic lesioning of the hypothalamic sleep-promoting cell group, the ventrolateral preoptic (VLPO) nucleus [26]. All rats were implanted with electrodes for recording electroencephalogram (EEG) and electromyogram (EMG) for assessing their sleep-wake status. A prelesion control EEG of the rats was continuously recorded for $24 \mathrm{~h}$ (13:00-13:00), 6 days after the EEG implantation. Wake-sleep states were manually scored, by an observer who was not aware of the histological results of the animals, in $12 \mathrm{~s}$ epochs based on the digitized EEG of each rat. Wakefulness was identified by the presence of desynchronizedEEG.

Animals were anesthetized with chloral hydrate and positioned in a stereotaxic frame. The skull was reexposed, and the tip of a fine glass micropipette was placed at the VLPO stereotaxic coordinates (AP - 0.6 from bregma, $\mathrm{L} \pm 1.00$, DV 8.5 as per the rat atlas of Paxinos and Watson). Two hundred nanoliters of $0.1 \%$ orexin-Bsaporin (Advanced Targeting Systems, CA, USA) or saline as a control were injected by air pressure and the pipette was slowly removed after $2 \mathrm{~min}$. In this manner, each rat received bilateral injections targeted at the VLPO. Two weeks after the surgical procedure, rats were habituated to the recording conditions and sleepwake recordings (EEG/EMG) were performed for $24 \mathrm{~h}$. In order to assess the cumulative effect of chronic sleep deprivation, CSD recordings (as described below) were performed 6 weeks or 12 weeks after VLPO lesions. Following CSD characterization, rats were perfused with saline $(100 \mathrm{ml})$ followed by $10 \%$ formalin $(300 \mathrm{ml})$ transcardially and their brains were cut in the coronal plane on a freezing microtome into four evenly spaced series of $40 \mu \mathrm{m}$ coronal sections and Nissl stained as described previously $[26,27]$. VLPO lesioning was considered successful in cases of $>70 \%$ VLPO neuron loss bilaterally, which has been shown repeatedly in multiple studies to cause a 50\% decrease in NREM sleep time [26]. The control group consists of rats with off-target lesions, and sham-lesioned (saline-injected) rats.

\section{Surgical preparation for CSD assessment}

Rodents were anesthetized with isoflurane $(2.5 \%$ induction, $1 \%$ maintenance, in $\left.70 \% \mathrm{~N}_{2} \mathrm{O} / 30 \% \mathrm{O}_{2}\right)$, and tracheostomized for mechanical ventilation (SAR-830, CWE, Ardmore, PA, USA). A femoral artery was cannulated for continuous mean arterial blood pressure recording (PowerLab; AD Instruments, Colorado Springs, CO, USA). Arterial blood gas and $\mathrm{pH}$ were maintained within normal limits by adjusting the ventilation parameters (Rapidlab 248 blood gas/pH analyzer, Siemens Healthcare Diagnostics, Tarrytown, NY, USA). Rectal temperature was maintained at 36-37 degrees Celsius using a thermostatically controlled heating pad (FHC, Bowdoinham, ME, USA). Rodents were placed in a stereotaxic frame (Stoelting, Wood Dale, IL, USA) and 3 burr holes were drilled bilaterally for electrophysiological recordings (recording site 2), as described previously (Fig. 1) [28]. 


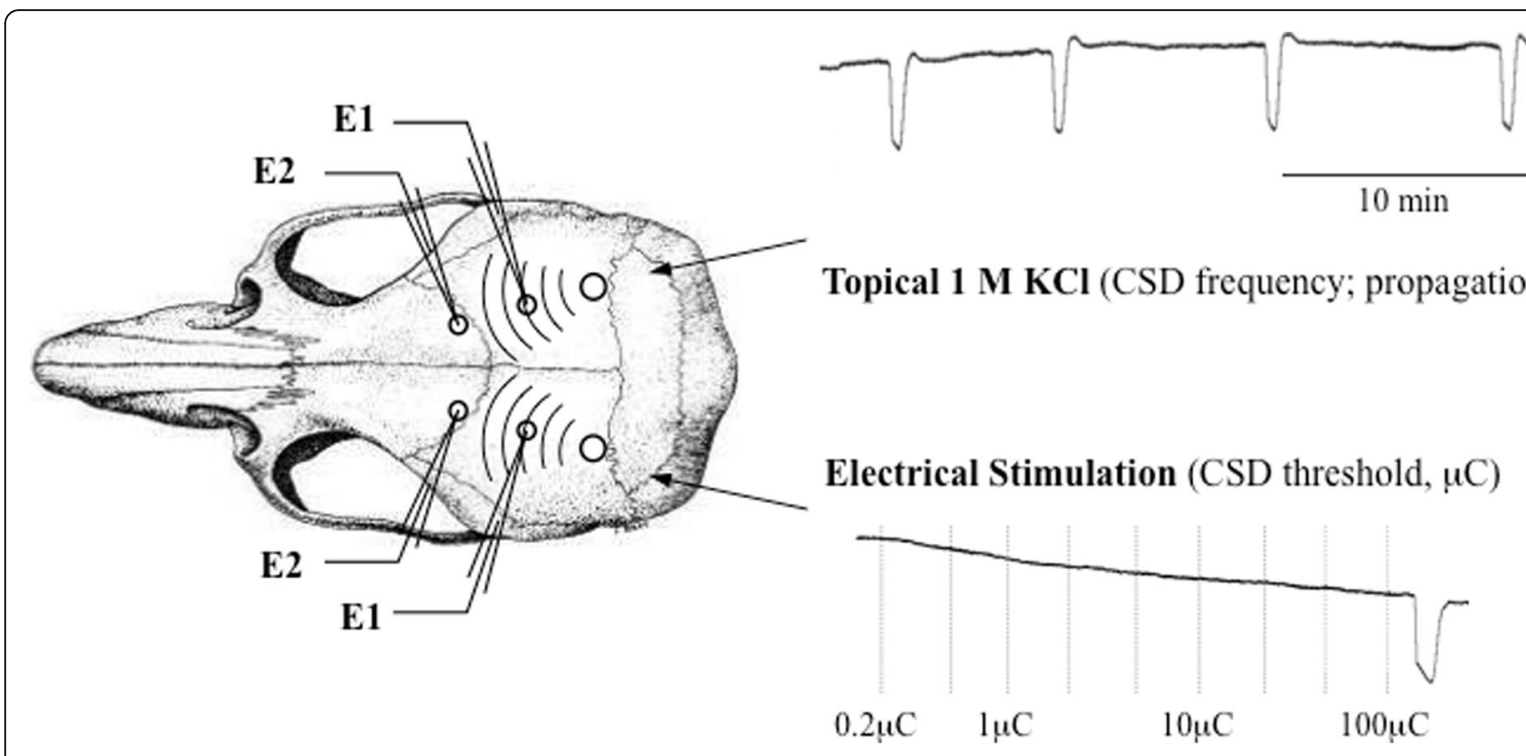

Fig. 1 Experimental setup for electrophysiological recordings. CSD, cortical spreading depolarization; E, electrode; $\mu C$, micro coulomb

\section{Electrophysiological CSD recordings}

All experiments were performed in a blinded fashion with respect to sleep status. Two glass capillary microelectrodes were placed to measure the potential difference between recording sites 1 and 2 on each side of the brain to record extracellular steady (DC) potential changes and electrocorticogram (FHC, Inc. Bowdoinham, ME), using a data acquisition system for off-line analysis (PowerLab; AD Instruments, Colorado Springs, MO, USA). The electrical stimulation threshold for CSD was assessed by direct cortical stimulation with a bipolar stimulation electrode placed on the occipital cortex $(400 \mu \mathrm{m}$ tip diameter, $1 \mathrm{~mm}$ tip separation; Frederick Haer Company, Bowdoin, ME, USA). Using a stimulator (GrassInstruments, West Warwick, RI, USA) and a constant current unit (WPI, Sarasota, FL, USA), cathodal squared pulses of increasing intensity and duration (1$4000 \mu \mathrm{C}$ ) were applied at $4 \mathrm{~min}$ intervals, until CSD occurred. For $\mathrm{KCl}$-induced CSD susceptibility, a $1.5 \mathrm{~mm}$ cotton ball soaked with $1 \mathrm{M} \mathrm{KCl}$ was placed on the pial surface of the contralateral hemisphere and replaced every $15 \mathrm{~min}$. The total number of CSDs during $60 \mathrm{~min}$ of continuous topical $\mathrm{KCl}$ application was counted. The DC shift amplitude and duration (sec) (measured at half maximal amplitude) of the first CSD, as well as the propagation speed $(\mathrm{mm} / \mathrm{min})$, the propagation failure (\%) and the cumulative duration (sec) of all CSDs during continuous $\mathrm{KCl}$ application were calculated.

\section{Statistics}

Data were analyzed with SPSS (version 11.0). Using a general linear model of covariance analysis (ANACOVA), we tested for an effect of the independent variable sleep deprivation on the dependent variables CSD threshold, frequency and propagation speed. Other electrophysiological measures of CSD and systemic physiological data were compared among groups using one-way ANOVA. Data are shown as mean \pm standard deviation, and $p<0.05$ was considered significant.

\section{Results}

Mean arterial blood pressure, arterial $\mathrm{pCO}_{2}$ and $\mathrm{pH}$ were within normal physiological range and did not differ among groups (Table 1).

\section{Acute sleep deprivation increased CSD susceptibility}

Twelve hours but not $6 \mathrm{~h}$ sleep deprivation significantly reduced the electrical threshold for CSD induction,

Table 1 Physiological parameters

\begin{tabular}{lllll}
\hline Group & pH & paCO2 & paO2 & BP \\
Control & $7.41 \pm 0.03$ & $42 \pm 2$ & $117 \pm 18$ & $83 \pm 9$ \\
6h sleep deprivation & $7.41 \pm 0.02$ & $40 \pm 3$ & $123 \pm 28$ & $92 \pm 11$ \\
12h sleep deprivation & $7.41 \pm 0.03$ & $39 \pm 2$ & $119 \pm 22$ & $89 \pm 8$ \\
Group & $\mathbf{p H}$ & $\mathbf{p a C O 2}$ & $\mathbf{p a O 2}$ & $\mathrm{BP}$ \\
VLPO-lesioned & $7.42 \pm 0.04$ & $39 \pm 6$ & $132 \pm 21$ & $99 \pm 12$ \\
Control & $7.39 \pm 0.05$ & $41 \pm 8$ & $118 \pm 37$ & $90 \pm 17$
\end{tabular}

Physiological parameters did not differ between groups. A) Acute sleep deprivation in rats: $6 \mathrm{~h}$ controls and $12 \mathrm{~h}$ controls were pooled for statistical analysis, as no significant difference was found between the two control groups; B) Chronic sleep deprivation in VLPO-lesioned rats. Control animals underwent a sham procedure with saline injection into their VLPO The arterial blood gas $(\mathrm{mmHg}$ ) and $\mathrm{pH}$ values were measured at the beginning and end of each $\mathrm{KCl}$ stimulation period, and before electrical stimulation, for a total of 6 measurements per experiment. Data are presented as average \pm SD. Arterial blood pressure (BP) values $(\mathrm{mmHg})$ are the average of the $\mathrm{KCl}$ application and electrical stimulation recording periods 
when compared to controls $(p=0.037$ and $p=0.095$, respectively; Fig. 2). Data from $6 \mathrm{~h}$ and $12 \mathrm{~h}$ control animals were pooled as there were no differences for any study endpoint. Overall, sleep deprived rats showed a reduced electrical threshold of CSD compared to controls ( $p=$ 0.015) (Table 2). Continuous application of $1 \mathrm{M} \mathrm{KCl}$ on the occipital cortex evoked repetitive CSDs in all groups. Control rats $(n=30 ; 6 \mathrm{~h}$ and $12 \mathrm{~h})$ developed $14.4 \pm 2.0$ CSDs/hour. Both $6 \mathrm{~h}(n=17)$ and $12 \mathrm{~h}(n=11)$ sleepdeprivation increased CSD frequency compared to respective-interleaved controls $(16.9 \pm 3.5$ and $17.9 \pm 2.1$, respectively; $p=0.003$ for both; Fig. 3), while other electrophysiological properties of CSD were unchanged. Recordings from $6 \mathrm{~h}$ or $12 \mathrm{~h}$ sleep-deprived rats and controls did not differ for propagation speed $(4.6 \pm 0.7,4.5 \pm 0.5$ and $4.2 \pm 0.6)$ and propagation failure $(31.9 \pm 13.2,30.0 \pm 11.8$ and $31.5 \pm 11.8$ ) (Table 3), neither for the duration of first CSD $(23.4 \pm 3.8,23.9 \pm 5.1$ and $23.1 \pm 4.6)$ or cumulative CSD duration $(292.6 \pm 79.1,297.1 \pm 48.1$ and $267.6 \pm 73.9)$ (Additional files: Figures 1 and 2). Direct cortical cathodal stimulation with stepwise escalating intensities and durations triggered CSD in all rats.

\section{Chronic sleep deprivation did not affect CSD susceptibility}

Histological analysis showed that VLPO lesioning reduced the number of intact VLPO neurons, as detailed in Fig. 4.
Table 2 Effect of acute sleep deprivation on CSD electrical threshold

\begin{tabular}{|c|c|c|c|}
\hline \multirow[t]{2}{*}{ Group } & \multirow[t]{2}{*}{$\mathrm{n}$} & \multicolumn{2}{|c|}{ CSD Threshold $(\mu \mathrm{C})$} \\
\hline & & mean (range) & average $\pm S D$ \\
\hline Control & 19 & $50(1-800)$ & $108 \pm 227$ \\
\hline $6 \mathrm{~h}$ sleep deprivation & 11 & $20(1-400)$ & $63 \pm 116$ \\
\hline $12 \mathrm{~h}$ sleep deprivation & 14 & $10(1-300)^{*}$ & $41 \pm 76^{*}$ \\
\hline $6 \mathrm{~h}$ and $12 \mathrm{~h}$ sleep deprivation & 25 & $15(1-400)^{*}$ & $50 \pm 93^{*}$ \\
\hline
\end{tabular}

Sleep deprivation of $12 \mathrm{~h}$ but not $6 \mathrm{~h}$ decreased the electrical CSD threshold. All controls ( $6 \mathrm{~h}$ controls and $12 \mathrm{~h}$ controls) were pooled for statistical analysis, as no significant difference was found between the two control groups ${ }^{*} p<0.01$ vs. control

Continuous topical $\mathrm{KCl}$ application evoked repetitive CSDs in all rats. There was no difference between VLPO lesioned rats and controls, and there was no correlation between the number of intact VLPO neurons and CSD electrical threshold $(1100 \pm 1295$ vs. $767 \pm 320$; Fig. $4 a)$, CSD frequency $(10.5 \pm 4.3$ vs. $9.7 \pm 4.1$; Fig. $4 \mathrm{~b})$ or for any other CSD parameter (propagation speed: $3.0 \pm 0.5$ vs. $3.3 \pm 0.8$; duration of first CSD: $23.8 \pm 7.8$ vs. $26.3 \pm 7.8$; cumulative CSDs duration: $174.2 \pm 72.8$ vs. $175.1 \pm 44.7$ ) (Additional files: Figure 3a and b).

\section{Discussion}

We investigated the effect of sleep deprivation on CSD susceptibility, the electrophysiological correlate of

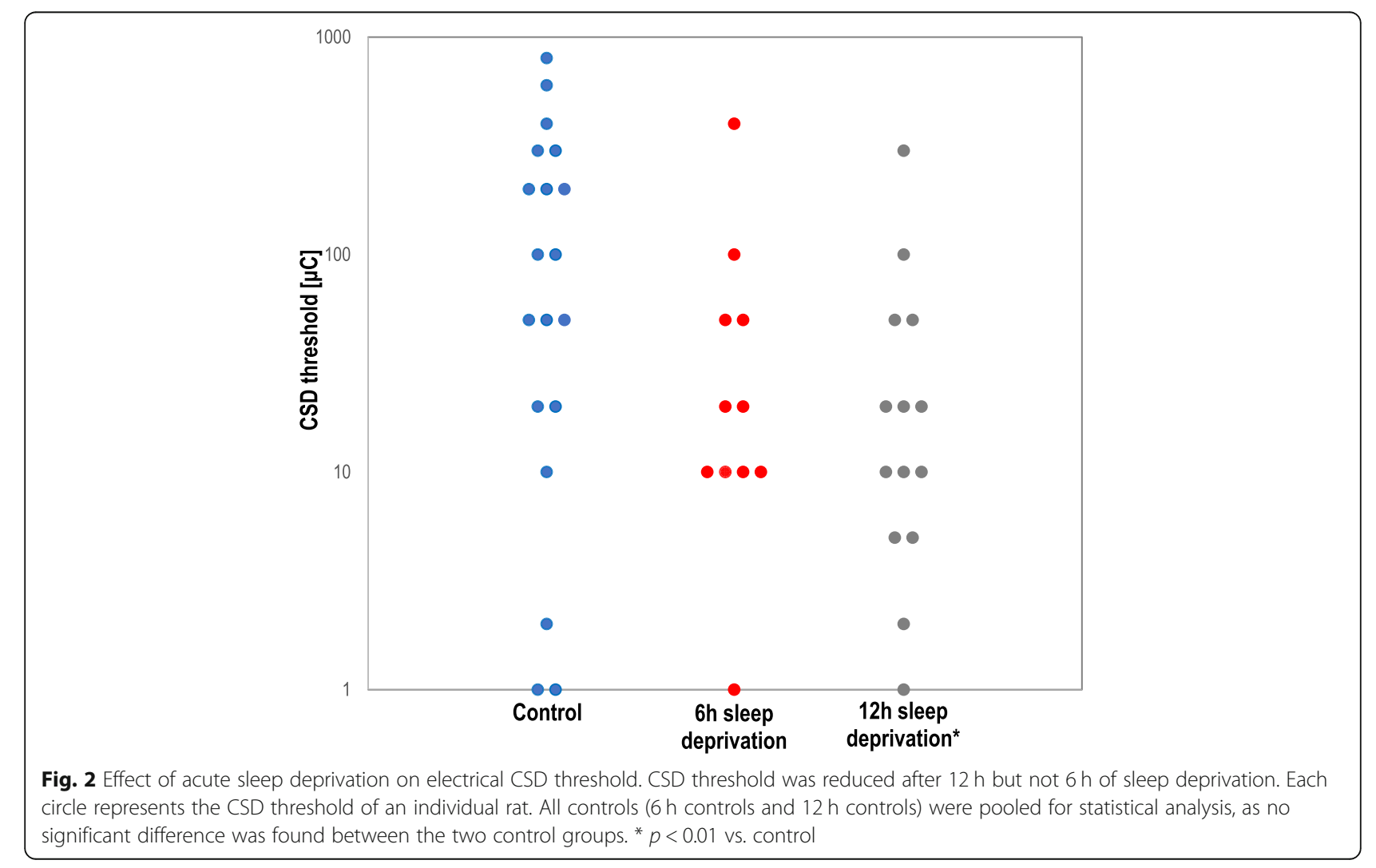




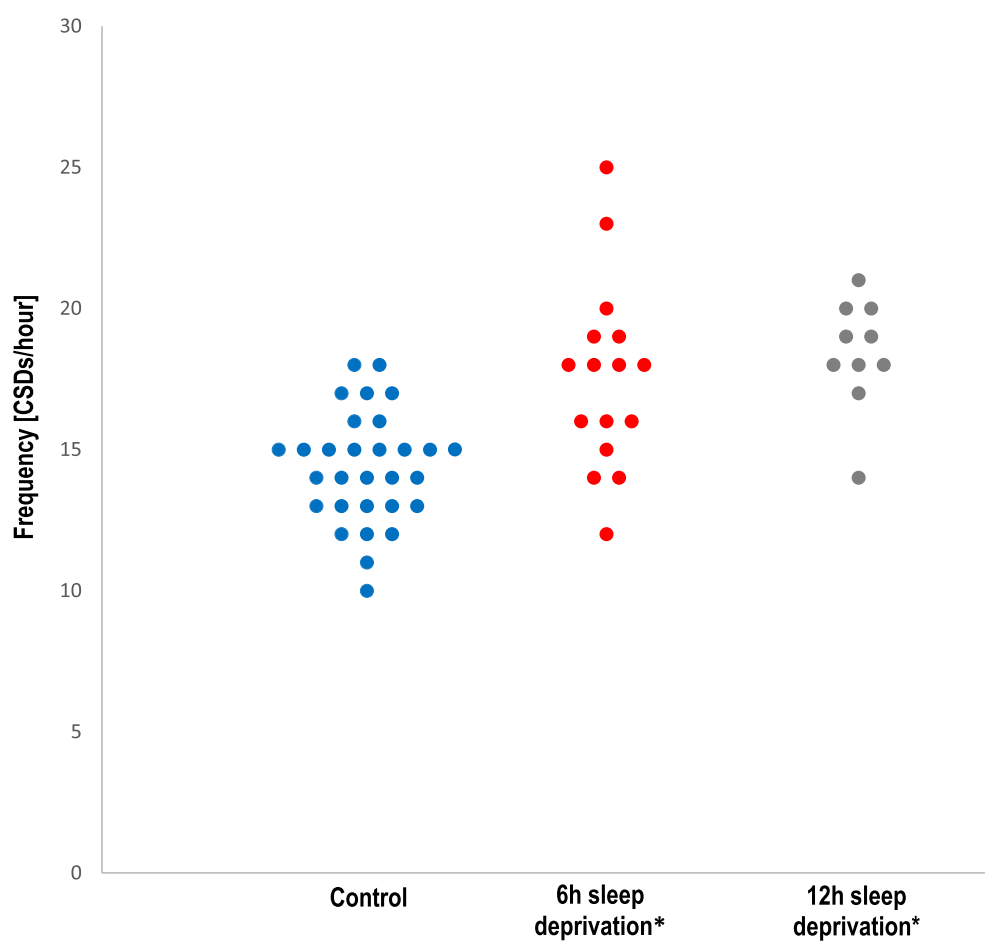

Fig. 3 Effect of acute sleep deprivation on CSD frequency. Both $6 \mathrm{~h}$ and $12 \mathrm{~h}$ of sleep deprivation increased the frequency of CSD during topical continuous application of $\mathrm{KCl}$. Each circle represents the CSD frequency of an individual rat. All controls ( $6 \mathrm{~h}$ controls and $12 \mathrm{~h}$ controls) were pooled for statistical analysis, as no significant difference was found between the two control groups. ${ }^{*} p=0.03$ vs. control

migraine aura. Our experiments show that acute sleep deprivation for both 6 and $12 \mathrm{~h}$, dose-dependently, increases CSD susceptibility in rats, as evidenced by a reduced electrical threshold for CSD induction in the $12 \mathrm{~h}$ sleep deprived group, and an increased frequency of CSD upon continuous topical application of $\mathrm{KCl}$ in both $12 \mathrm{~h}$ and $6 \mathrm{~h}$ sleep deprived groups. In order to maximize reliability and relevance of our findings, CSD susceptibility was tested using two well-established independent but complementary experimental paradigms $(\mathrm{KCl}$ application and electrical stimulation) that provided coherent results.

Clinically, sleep deprivation or excessive sleep, as well as other sleep disturbances are among to the most common attack triggers reported by patients with primary headaches (e.g. migraine without aura [25, 29], migraine with aura [30], familial hemiplegic migraine [31], tension-type headache [32, 33]). Conversely, sleep is associated with the resolution or relief of migraine attacks $[34,35]$. Over half of reported migraine attacks are followed by daytime sleepiness and migraineurs often choose to sleep looking for relief from their headache [35]. Similarly, in animals, CSD is followed by an increase of NREM sleep phase duration, suggesting an increased need for sleep after an attack [36]. Patients with chronic migraine report shorter nightly sleep times than those with episodic migraine, and are more likely to exhibit difficulties falling asleep, staying asleep, are more prone to develop sleep triggered headache, and choose to sleep because of headache [35, 37]. The quality of sleep is decreased in adults with migraine [38, 39 ] and over half of them report difficulty initiating and maintaining sleep, at least occasionally [35]. Short sleepers, who routinely sleep $6 \mathrm{~h}$ or less per night,

Table 3 Effect of sleep deprivation on CSD propagation speed and propagation failure

\begin{tabular}{llll}
\hline Group & $\mathrm{n}$ & Propagation speed (mm/min) & Propagation Failure (\%) \\
\hline Control & 30 & $3.0 \pm 0.4$ & $31 \pm 12$ \\
6h sleep deprivation & 17 & $3.0 \pm 0.5$ & $32 \pm 13$ \\
$12 \mathrm{~h}$ sleep deprivation & 11 & $3.0 \pm 0.3$ & $30 \pm 12$ \\
\hline
\end{tabular}

Acute sleep deprivation did not affect propagation speed or propagation failure of CSD in rats. Control groups for $6 \mathrm{~h}$ and $12 \mathrm{~h}$ sleep deprivation were pooled for statistical analysis, as no significant difference was found between the two control groups

Measurements were made of the first CSD recorded after topical $\mathrm{KCl}$ application

Values are average $\pm S D$ 
A

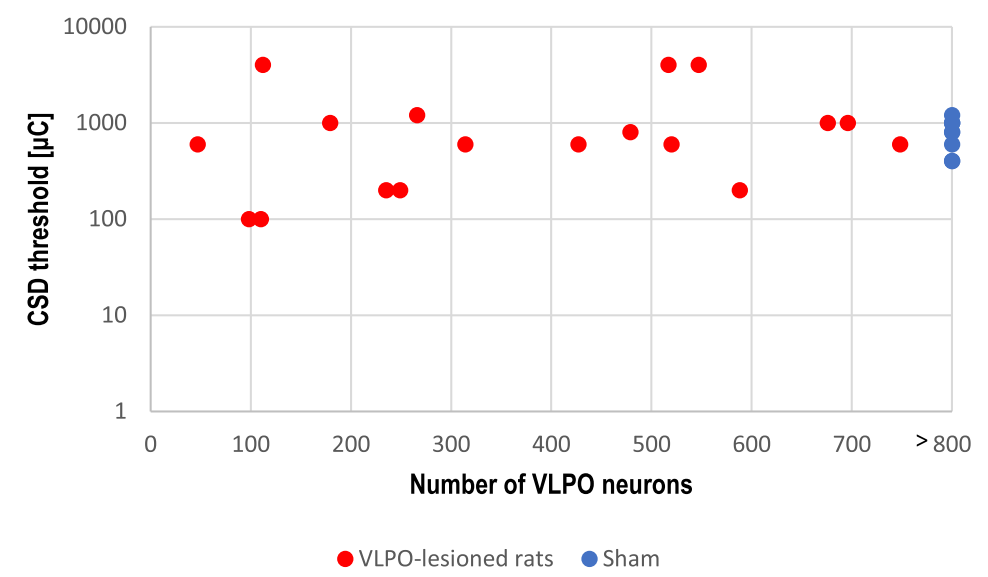

B

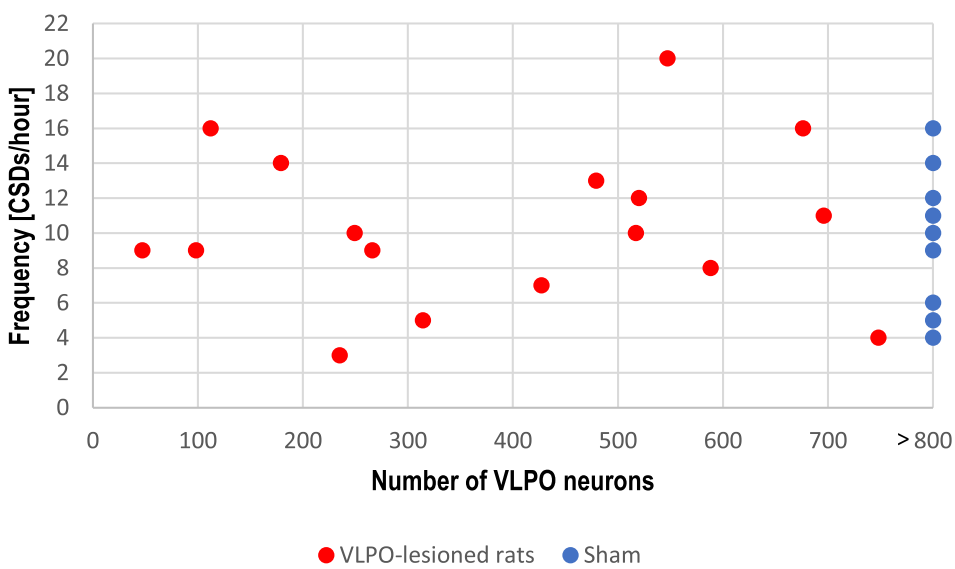

Fig. 4 CSD threshold and frequency in VLPO-lesioned rats. Electrical CSD threshold (a) and CSD frequency upon topical continuous KCl (b) were not altered in rats after chronic sleep deprivation, 6 or 12 weeks after lesioning of the ventrolateral preoptic nucleus. The $x$-axis indicates the number of intact VLPO neurons after the lesioning procedure. The number of VLPO neurons for sham animals was set to $>800$

exhibit more severe headache patterns and are more likely to develop morning headaches on awakening than individuals who sleep longer [35]. Taken together, it appears there is a relationship between migraine and sleep disturbance, with a possible cause-effect relationship not being entirely clear at this point.

Consistent with these epidemiological findings, increasing evidence suggests that sleep deprivation has adverse effects on several pathways involved in headache, including cortical excitability, neurotransmission and neurogenesis [40]. Sleep disturbance impairs endogenous pain-inhibitory function and increases spontaneous pain, in particular headache [41]. Lack of sleep has been shown to increase cortical excitability, as a possible mechanism to explain our findings of an increased CSD susceptibility in sleep-deprived rats. For example, $4 \mathrm{~h}$ of sleep deprivation has been shown to enhance intrinsic cortical activity and excitability in rats, possibly through a $\mathrm{Ca}^{2+}$-dependent mechanism [42]. Similarly, in healthy humans using single pulse transcranial magnetic stimulation, it has been observed that sleep deprivation enhances cortical excitability with reduction of short intracortical inhibition [43]. As a possible underlying mechanism, sleep deprivation has been shown to increase levels of the excitatory neurotransmitter glutamate in rat cerebral cortex [44]. Moreover, sleep deprivation induces an increase in the expression of glutamate receptors in rat hippocampus, which is involved in increased susceptibility of short and long-term depression in that area [45]. Glutamatergic mechanisms 
have been implicated in CSD susceptibility [46], and, thus, an increase in glutamatergic neurotransmission could explain the sleep deprivation-induced increase in CSD susceptibility. In addition, lack of sleep may enhance CSD susceptibility by inhibiting the $\mathrm{Na}^{+} / \mathrm{K}^{+}$ATPase in the setting of energy failure secondary to oxidative stress. The surge in adenosine triphosphate (ATP) levels, the energy currency of brain cells, occurs when neuronal activity is reduced, as during sleep. The levels of phosphorylated AMP-activated protein kinase (P-AMPK), important for cellular energy sensing and regulation, are lower during the sleep-induced ATP surge than during wake or sleep deprivation [47]. Accordingly, prolonged sleep deprivation significantly decreases the activity of anti-oxidative enzymes such as superoxide dismutase and glutathione peroxidase that regulate the level of reactive oxygen species [48] and has been shown to increase lipid peroxidation in the rat hippocampus, thalamus and hypothalamus, leading to a higher oxidative stress in these brain regions compared to others [49].

Another potential link between migraine, sleep deprivation and CSD is altered neurotransmitter dynamics. For example, adenosine has been implicated in migraine pathophysiology, because adenosine levels were shown to be elevated during migraine attacks and administration of adenosine can precipitate migraine attacks [15]. Moreover, the adenosine A2A receptor gene haplotype was found to be associated with migraine with aura [50]. Adenosine has been shown to be elevated after CSD in brain slices under conditions likely to trigger CSD in vivo, and adenosine receptor activation has been shown to be involved in the prolonged depression of synaptic transmission after CSD [51]. At the same time, a role for adenosine in sleep regulation has been suggested by studies showing a progressive increase in extracellular adenosine in the basal forebrain during prolonged wakefulness [52], possibly explaining the potential CSD-mediated negative effect of sleep deprivation on migraine.

The high prevalence of sleep disturbances in migraineurs could also depend in part on a dysregulation of the cyclic secretion of melatonin. During a migraine attack, the plasma levels of melatonin are decreased [53], and evidence suggests that administering melatonin to migraine sufferers relieves pain and decreases headache recurrence in some cases [54]. Accordingly, melatonin slows down retinal spreading depression [55] and can attenuate the process of trigeminovascular nociception induced by CSD in rats [56]. In addition, serotoninergic processes have been implicated in mediating the migraine promoting effect of sleep deprivation. Serotonin is a neuromodulator with a pivotal role in regulating several central nervous system activities, including pain threshold and sleep induction. Sleep deprivation causes an enhancement of serotonergic neurotransmission in the brain, as suggested in animal studies. In sleepdeprived rats, elevated serotonin levels have been measured in the hippocampus [57] and in serotonergic raphe nuclei [58], which, with their widespread cortical projections, are part of the monoaminergic wake promoting system. Accordingly, human in vivo studies showed that plasma levels of serotonin and its precursor tryptophan exhibit a significant increase during sleep deprivation compared to sleep [59] and that a single night of total sleep deprivation causes significant increases of serotonin $2 \mathrm{~A}$ receptor binding potentials in a variety of cortical regions [60]. Future experiments could aim to clarify the role of melatonin and serotonin in mediating the effect of sleep deprivation on CSD, for example by testing if melatonin supplementation or antiserotonergic drugs diminish or abrogate the sleep deprivation-induced increase in CSD susceptibility.

Recently, Kilic et al. reported that the enhanced susceptibility to CSD after sleep deprivation may be due to impaired $\mathrm{K}+$ and glutamate clearance by astrocytes consequent to sleep deprivation-induced suppression of glycogen use and synaptic energy substrate deficiency [61]. The authors demonstrated that sleep deprivation for $6 \mathrm{~h}$ using the same "gentle handling method" decreased threshold for CSD induction and prolonged the duration of CSDs without changing the CSD propagation speed and frequency, which, on the contrary, had increased in our experiments. Furthermore, this study reported that the decreased CSD thresholds could be recovered via the use of an alternate energy supply (D-glucose or L-lactate superfusion), linking decreased CSD thresholds to an activity/energy mismatch resulting from prolonged wakefulness [61]. An alternate energy supply was able to revert the enhancement of CSD susceptibility and reduced clearance of $\mathrm{K}+$ during synaptic activity. Differences between results of the Kilic study and ours could be attributed to species differences, because mice show a predominantly vasoconstrictive response to CSD, which is in contrast to the biphasic vascular response that is seen in humans or rats, used in our experiments. In addition, Kilic et al. administered urethane/xylazine as anesthetic, which has a different effect on cortical excitability than isoflurane, which was used in our study [62].

We also tested the effect of chronic sleep deprivation on CSD susceptibility in rats sustaining the loss of VLPO neurons, a previously validated model of chronic sleep restriction [26]. It is well established that the VLPO is a key sleep-promoting cell group in the hypothalamus, and, already in 1930, von Economo reported that lesions of this region cause prolonged insomnia in humans [63]. Neurons in the preoptic hypothalamus are important 
regulators of sleep onset and sleep maintenance [64]. VLPO is thought to play a major role in causing sleep by GABAA receptor-mediated hyperpolarization and inhibition of histaminergic neurons in the tuberomammillary nucleus [65], which are important for promoting wakefulness [66]. VLPO lesions induce long-lasting insomnia in rats, with a $60-70 \%$ decrease in delta power and a 50-60\% decrease in NREM sleep time [26]. VLPO lesion experiments allowed us to study the effect of chronic partial sleep loss on CSD without continual stressful experimental interventions, to avoid a possible confounding impact of stress on CSD. We here show that CSD susceptibility is not altered 6 weeks or 12 weeks after VLPO lesioning, suggesting that the effect of acute sleep deprivation on CSD is not mediated via reduced NREM sleep, that acute total sleep deprivation has a different effect on cortical excitability than chronic partial sleep restriction, and/or that compensatory mechanisms cause adaptation of cortical excitability within the chronic setting.

Our study has several limitations, including the fact that animal sleep deprivation models may not allow direct extrapolation to patients. However, gentle handling is very effective at inducing total sleep deprivation as determined by electroencephalography [67] and seems to be a valid model of typical sleep deprivation in humans. While the gentle handling method is less stressful than other methods that induce sleep deprivation, it still may be a cause of stress. It is therefore possible that the pathways induced by sleep deprivation in our animal model are different from those that occur in humans who consciously decide to stay awake or delay sleep. However, we feel that acute stress may not be important for our study endpoint, CSD susceptibility, as acute stress has recently been shown to not affect CSD susceptibility in rodents [68]. In addition, we used an invasive method to induce and record CSD, which may have affected our endpoint of CSD susceptibility. However, assessment of CSD susceptibility with electrocortical recordings, and CSD induction with $\mathrm{KCl}$ and electrical stimuli are the most established methods, used in many other respected studies in the field [17-19]. Another possible shortcoming is the fact that rats were anesthetized during CSD assessment, and it has been shown that anesthetics modify CSD threshold [62]. Future experiments could perform CSD recordings in the sleep-deprived awake nonanesthetized rat, using non-invasive techniques for CSD induction, such as optogenetics [69]. In addition, assessment of additional migraine surrogates might further underscore the relevance of our findings for migraine, such as monitoring of face grimacing [70], and measurement of blood levels of adenosine, melatonin or serotonin - factors that are important in migraine and might mediate the effect of sleep deprivation on CSD. Finally, future experiments that confirm our results in mutant mice carrying human migraine mutations, such as FHM, and/or in female rodents, could further underscore the clinical relevance of our findings.

\section{Conclusions}

Primary headaches and sleeping problems are highly prevalent and cause considerable social and familial challenges. Sleep disorders and migraine seem to share pathophysiological pathways with a bidirectional influence, making it difficult to discern cause and effect. This study shows that acute sleep deprivation enhances CSD susceptibility, similar to other migraine promoting factors such as female gonadal hormones or genetic mutations. Acute sleep deprivation increases CSD frequency during topical $\mathrm{KCl}$ application and decreases the electrical threshold of CSD upon electrical stimulation. Furthermore, our results show that partial chronic sleep restriction/fragmentation by VLPO-lesioning, with predominant loss of NREM sleep, does not affect CSD susceptibility. These findings further underscore the importance of CSD as a migraine substrate, and open up new potential therapeutic avenues, suggesting that headache management should identify and treat associated sleep disorders.

\section{Supplementary information}

Supplementary information accompanies this paper at https://doi.org/10. 1186/s10194-020-01155-w.

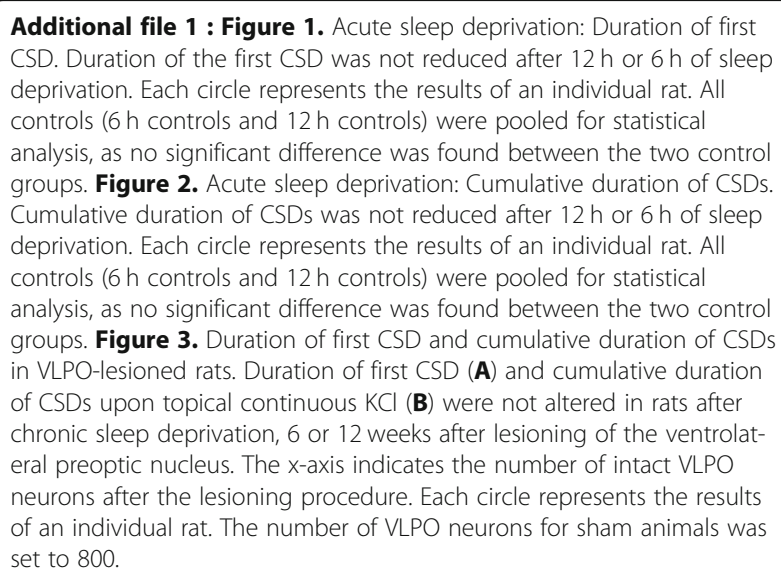

\section{Abbreviations}

ATP: Adenosine triphosphate; CADASIL: Cerebral autosomal dominant arteriopathy with subcortical infarcts and leukoencephalopathy; CSD: Cortical spreading depolarization; DC: Extracellular steady; NREM: Nonrapid-eye movement; REM: Rapid-eye movement; VLPO: Ventrolateral preoptic nucleus

\section{Acknowledgements}

Not applicable.

Authors' contributions

AN: Conception of the study; Acquisition, analysis and interpretation of data; Drafting and revising the manuscript. JLS: Conception of the study; Acquisition, analysis and interpretation of data. $\mathrm{TH}$ : Acquisition, analysis and interpretation of data. ESY: Acquisition, analysis and interpretation of data. IR: 
Acquisition, analysis of data. AA: Acquisition, analysis of data. LSG: Acquisition, analysis of data. LP: Acquisition, analysis of data. NY: Acquisition, analysis of data. NC: Conception of the study; Design of the study; Revision of the manuscript. RV: Conception of the study; Design of the study; Revision of the manuscript. NLC: Conception of the study; Design of the study; Revision of the manuscript. CA: Conception of the study; Design of the study; Analysis and interpretation of data; Revision of the manuscript. PM: Conception of the study; Revision of the manuscript. MAM: Conception of the study; Design of the study; Analysis and interpretation of data; Revision of the manuscript. KEH: Conception of the study; Design of the study; Analysis and interpretation of data; Drafting and revising the manuscript. The author(s) read and approved the final manuscript.

\section{Funding}

This work was funded in part by the American Heart Association (10SDG2610275, KEH; 10SDG2600218, IA), the Massachusetts General Hospital (Claflin Distinguished Award, KEH).

This work was funded in part by the Department of Clinical and Molecular Medicine, Sapienza University of Rome.

\section{Availability of data and materials}

Dataset available from the corresponding author on reasonable request.

\section{Ethics approval and consent to participate}

All experimental procedures were carried out in accordance with the Guide for Care and Use of Laboratory Animals (NIH Publication No. 85-23, 1996), and were approved by the institutional review board (MGH Subcommittee on Research Animal (are, SRAC) and Institutional Animal Care and Use Committee of Beth Israel Deaconess Medical Center.

\section{Consent for publication}

Not applicable.

\section{Competing interests}

The authors declare that they have no competing interests.

\section{Author details}

${ }^{1}$ Neurovascular Research Laboratory, Department of Radiology, Massachusetts General Hospital, Harvard Medical School, Charlestown, MA, USA. ${ }^{2}$ Department of Clinical and Molecular Medicine, Sapienza University of Rome, Rome, Italy. ${ }^{3}$ Department of Neurology, Beth Israel Deaconess Medical Center, Harvard Medical School, Boston, MA, USA. ${ }^{4}$ Department of Pathology, Boston Children's Hospital, Boston, MA, USA. ${ }^{5}$ Stroke Service and Neuroscience Intensive Care Unit, Department of Neurology, Massachusetts General Hospital, Harvard Medical School, Boston, MA, USA. ${ }^{6}$ Department of Radiology, and Department of Neurology, Massachusetts General Hospital, Harvard Medical School, Boston, MA, USA. 'Department of Radiology, Massachusetts General Hospital, Harvard Medical School, 55 Fruit Street, Boston, MA 02114, USA.

\section{Received: 19 March 2020 Accepted: 1 July 2020}

Published online: 06 July 2020

\section{References}

1. Lipton RB, Bigal ME, Diamond M, Freitag F, Reed ML, Stewart WF, Group AA (2007) Migraine prevalence, disease burden, and the need for preventive therapy. Neurology. 68:343-349

2. Blumenfeld AM, Varon SF, Wilcox TK, Buse DC, Kawata AK, Manack A, Goadsby PJ, Lipton RB (2011) Disability, hrqol and resource use among chronic and episodic migraineurs: results from the international burden of migraine study (ibms). Cephalalgia. 31:301-315

3. Bloudek LM, Stokes M, Buse DC, Wilcox TK, Lipton RB, Goadsby PJ, Varon SF, Blumenfeld AM, Katsarava Z, Pascual J, Lanteri-Minet M, Cortelli P, Martelletti $P$ (2012) Cost of healthcare for patients with migraine in five european countries: results from the international burden of migraine study (IBMS). J Headache Pain. 13:361-378

4. GBD. Disease and injury incidence and prevalence collaborators (2017) Global, regional, and national incidence, prevalence, and years lived with disability for 328 diseases and injuries for 195 countries, 1990-2016: a systematic analysis for the global burden of disease study 2016. Lancet 390(10100):1211-1259
5. Steiner TJ, Stovner LJ, Vos T, Jensen R, Katsarava Z (2018) Migraine is first cause of disability in under 50s: will health politicians now take notice? J Headache Pain 19(1):17

6. Manack AN, Buse DC, Lipton RB (2011) Chronic migraine: epidemiology and disease burden. Curr Pain Headache Rep 15:70-78

7. Bigal ME, Lipton RB (2008) Concepts and mechanisms of migraine chronification. Headache. 48:7-15

8. Odegard SS, Engstrom M, Sand T, Stovner LJ, Zwart JA, Hagen K (2010) Associations between sleep disturbance and primary headaches: the third Nord-Trondelag health study. J Headache Pain. 11:197-206

9. Wober C, Wober-Bingol C (2010) Triggers of migraine and tension-type headache. Handb Clin Neurol 97:161-172

10. Reynolds AC, Banks S (2010) Total sleep deprivation, chronic sleep restriction and sleep disruption. Prog Brain Res 185:91-103

11. Aguggia M, Cavallini M, Divito N, Ferrero M, Lentini A, Montano V, Tinebra MC, Saracco MG, Valfre W (2011) Sleep and primary headaches. Neurol Sci 32(Suppl 1):S51-S54

12. Rains JC, Poceta JS (2012) Sleep-related headaches. Neurol Clin 30:12851298

13. Bigal ME, Lipton RB (2009) What predicts the change from episodic to chronic migraine? Curr Opin Neurol 22:269-276

14. Calhoun AH, Ford S (2007) Behavioral sleep modification may revert transformed migraine to episodic migraine. Headache. 47:1178-1183

15. Guieu R, Devaux C, Henry H, Bechis B, Pouget J, Mallet D, Sampieri F, Juin M, Gola R, Rochat H (1998) Adenosine and migraine. Can J Neurol Sci 25(1): $55-58$

16. Leão AA (1944) Spreading depression of activity in cerebral cortex. J Neurophysiol 7:359-390

17. Pietrobon D, Moskowitz MA (2013) Pathophysiology of migraine. Annu Rev Physiol 75:365-391

18. Eikermann-Haerter K, Dilekoz E, Kudo C, Savitz SI, Waeber C, Baum MJ, Ferrari MD, van den Maagdenberg AM, Moskowitz MA, Ayata C (2009) Genetic and hormonal factors modulate spreading depression and transient hemiparesis in mouse models of familial hemiplegic migraine type 1. J Clin Invest 119:99-109

19. Eikermann-Haerter K, Yuzawa I, Dilekoz E, Joutel A, Moskowitz MA, Ayata C (2011) Cerebral autosomal dominant arteriopathy with subcortical infarcts and leukoencephalopathy syndrome mutations increase susceptibility to spreading depression. Ann Neurol 69:413-418

20. Eikermann-Haerter K, Baum MJ, Ferrari MD, van den Maagdenberg AM, Moskowitz MA, Ayata C (2009) Androgenic suppression of spreading depression in familial hemiplegic migraine type 1 mutant mice. Ann Neurol 66:564-568

21. Lindquist BE, Shuttleworth CW (2012) Adenosine receptor activation is responsible for prolonged depression of synaptic transmission after spreading depolarization in brain slices. Neuroscience. 223:365-376

22. Lindquist BE, Shuttleworth CW (2017) Evidence that adenosine contributes to Leao's spreading depression in vivo. J Cereb Blood Flow Metab 37(5): 1656-1669

23. Delaruelle Z, Ivanova TA, Khan S, Negro A, Ornello R, Raffaelli B, Terrin A, Mitsikostas DD, Reuter U (2018) European Headache Federation School of Advanced Studies (EHF-SAS). Male and Female Sex Hormones in Primary Headaches. J Headache Pain 19(1):117

24. Tobler I, Jaggi K (1987) Sleep and eeg spectra in the Syrian hamster (mesocricetus auratus) under baseline conditions and following sleep deprivation. J Comp Physiol A 161:449-459

25. Andress-Rothrock D, King W, Rothrock J (2010) An analysis of migraine triggers in a clinic-based population. Headache. 50:1366-1370

26. Lu J, Greco MA, Shiromani P, Saper CB (2000) Effect of lesions of the ventrolateral preoptic nucleus on NREM and REM sleep. J Neurosci 20(10): 3830-3842

27. Vetrivelan R, Fuller PM, Yokota S, Lu J, Saper CB (2012) Metabolic effects of chronic sleep restriction in rats. Sleep. 35(11):1511-1520

28. Ayata C, Jin H, Kudo C, Dalkara T, Moskowitz MA (2006) Suppression of cortical spreading depression in migraine prophylaxis. Ann Neurol 59:652-661

29. Kelman $L$ (2007) The triggers or precipitants of the acute migraine attack. Cephalalgia. 27:394-402

30. Hauge AW, Kirchmann M, Olesen J (2011) Characterization of consistent triggers of migraine with aura. Cephalalgia. 31:416-438

31. Hansen JM, Hauge AW, Ashina M, Olesen J (2011) Trigger factors for familial hemiplegic migraine. Cephalalgia. 31:1274-1281 
32. Haque B, Rahman KM, Hoque A, Hasan AT, Chowdhury RN, Khan SU, Alam MB, Habib M, Mohammad QD (2012) Precipitating and relieving factors of migraine versus tension type headache. BMC Neurol 12:82

33. Wang J, Huang Q, Li N, Tan G, Chen L, Zhou J (2013) Triggers of migraine and tension-type headache in China: a clinic-based survey. Eur J Neurol 20: 689-696

34. Houle TT, Butschek RA, Turner DP, Smitherman TA, Rains JC, Penzien DB (2012) Stress and sleep duration predict headache severity in chronic headache sufferers. Pain. 153:2432-2440

35. Kelman L, Rains JC (2005) Headache and sleep: examination of sleep patterns and complaints in a large clinical sample of migraineurs. Headache 45:904-910

36. Faraguna U, Nelson A, Vyazovskiy W, Cirelli C, Tononi G (2010) Unilateral cortical spreading depression affects sleep need and induces molecular and electrophysiological signs of synaptic potentiation in vivo. Cereb Cortex 20: 2939-2947

37. Sancisi E, Cevoli S, Vignatelli L, Nicodemo M, Pierangeli G, Zanigni S, Grimaldi D, Cortelli P, Montagna P (2010) Increased prevalence of sleep disorders in chronic headache: a case-control study. Headache. 50:1464-1472

38. Karthik N, Kulkarni GB, Taly AB, Rao S, Sinha S (2012) Sleep disturbances in 'migraine without aura'--a questionnaire based study. J Neurol Sci 321:73-76

39. Seidel S, Hartl T, Weber M, Matterey S, Paul A, Riederer F, Gharabaghi M, Wöber- Bingöl C, Wöber C; PAMINA Study Group. Quality of sleep, fatigue and daytime sleepiness in migraine - a controlled study. Cephalalgia. 2009; 29:662-9

40. Palma JA, Urrestarazu E, Iriarte J (2013) Sleep loss as risk factor for neurologic disorders: a review. Sleep Med 14:229-236

41. Smith MT, Edwards RR, McCann UD, Haythornthwaite JA (2007) The effects of sleep deprivation on pain inhibition and spontaneous pain in women. Sleep. 30:494-505

42. Vyazovskiy W, Olcese U, Lazimy YM, Faraguna U, Esser SK, Williams JC, Cirelli C, Tononi G (2009) Cortical firing and sleep homeostasis. Neuron. 63(6):865-878

43. Kreuzer P, Langguth B, Popp R, Raster R, Busch V, Frank E, Hajak G, Landgrebe M (2011) Reduced intra-cortical inhibition after sleep deprivation: a transcranial magnetic stimulation study. Neurosci Lett 493(3):63-66

44. Bettendorff $L$, Sallanon-Moulin M, Touret M, Wins P, Margineanu L, Schoffeniels E (1996) Paradoxical sleep deprivation increases the content of glutamate and glutamine in rat cerebral cortex. Sleep. 19(1):65-71

45. Tadavarty R, Rajput PS, Wong JM, Kumar U, Sastry BR (2011) Sleepdeprivation induces changes in $\mathrm{GABA}(\mathrm{B})$ and mGlu receptor expression and has consequences for synaptic long-term depression. PLoS One 6(9):e24933

46. Pietrobon D, Moskowitz MA (2014) Chaos and commotion in the wake of cortical spreading depression and spreading Depolarizations. Nat Rev Neurosci 15(6):379-393

47. Dworak M, McCarley RW, Kim T, Kalinchuk AV, Basheer R (2010) Sleep and brain energy levels: ATP changes during sleep. J Neurosci 30:9007-9016

48. Ramanathan L, Gulyani S, Nienhuis R, Siegel JM (2002) Sleep deprivation decreases superoxide dismutase activity in rat hippocampus and brainstem. Neuroreport. 13:1387-1390

49. Singh R, Kiloung J, Singh S, Sharma D (2008) Effect of paradoxical sleep deprivation on oxidative stress parameters in brain regions of adult and old rats. Biogerontology. 9:153-162

50. Hohoff C, Marziniak M, Lesch KP, Deckert J, Sommer C, Mössner R (2007) An adenosine $\mathrm{A} 2 \mathrm{~A}$ receptor gene haplotype is associated with migraine with aura. Cephalalgia. 27(2):177-181

51. Lindquist BE, Shuttleworth CW (2014) Spreading depolarization-induced adenosine accumulation reflects metabolic status in vitro and in vivo. J Cereb Blood Flow Metab 34(11):1779-1790

52. Leenaars CCH, Savelyev SA, Van der Mierden S, Joosten RNJMA, Dematteis M, Porkka-Heiskanen T, Feenstra MGP Intracerebral Adenosine During Sleep Deprivation: A Meta-Analysis and New Experimental Data J Circadian Rhythms 2018;16:11

53. Masruha MR, de Souza Vieira DS, Minett TS, Cipolla-Neto J, Zukerman E, Vilanova LC, Peres MF (2008) Low urinary 6-sulphatoxymelatonin concentrations in acute migraine. J Headache Pain. 9:221-224

54. Wilhelmsen M, Amirian I, Reiter RJ, Rosenberg J, Gögenur I (2011) Analgesic effects of melatonin: a review of current evidence from experimental and clinical studies. J Pineal Res 51:270-277

55. Ebert E, Hanke W, Wiedemann M (1999) Fernandes de Lima VM. Biphasic effects of melatonin on the propagation of excitation waves in the chicken retina. Neurosci Lett 268:37-40
56. le Grand SM, Patumraj S, Phansuwan-Pujito P, Srikiatkhachorn A (2006) Melatonin inhibits cortical spreading depression-evoked trigeminal nociception. Neuroreport. 17:1709-1713

57. Peñalva RG, Lancel M, Flachskamm C, Reul JM, Holsboer F, Linthorst AC (2003) Effect of sleep and sleep deprivation on serotonergic neurotransmission in the hippocampus: a combined in vivo microdialysis/ EEG study in rats. Eur J Neurosci 17(9):1896-1906

58. Alfaro-Rodríguez A, González-Piña R, González-Maciel A, Arch-Tirado E (2006) Serotonin and 5-hydroxy-indole-acetic acid contents in dorsal raphe and suprachiasmatic nuclei in normal, malnourished and rehabilitated rats under 24 h of sleep deprivation. Brain Res 1110(1):95-101

59. Davies SK, Ang JE, Revell VL, Holmes B, Mann A, Robertson FP, Cui N, Middleton B, Ackermann K, Kayser M, Thumser AE, Raynaud Fl, Skene DJ (2014) Effect of sleep deprivation on the human metabolome. Proc Natl Acad Sci U S A 111(29):10761-10766

60. Elmenhorst D, Kroll T, Matusch A, Bauer A (2012) Sleep deprivation increases cerebral serotonin 2A receptor binding in humans. Sleep. 35(12):1615-1623

61. Kilic K, Karatas H, Dönmez-Demir B, Eren-Kocak E, Gursoy-Ozdemir Y, Can A, Petit JM, Magistretti PJ, Dalkara T (2018) Inadequate brain glycogen or sleep increases spreading depression susceptibility. Ann Neurol 83(1):61-73

62. Kudo C, Toyama M, Boku A, Hanamoto H, Morimoto Y, Sugimura M, Niwa H (2013) Anesthetic effects on susceptibility to cortical spreading depression. Neuropharmacology. 67:32-36

63. von Economo C (1930) Sleep as a problem of localization. J Nerv Ment Dis 71:249-259

64. Szymusiak R, Gvilia, McGinty D (2007) Hypothalamic control of sleep. Sleep Med 8(4):291-301

65. Yang QZ, Hatton GI (1997) Electrophysiology of excitatory and inhibitory afferents to rat histaminergic tuberomammillary nucleus neurons from hypothalamic and forebrain sites. Brain Res 773(1-2):162-172

66. Steininger TL, Alam MN, Gong H, Szymusiak R, McGinty D (1999) Sleepwaking discharge of neurons in the posterior lateral hypothalamus of the albino rat. Brain Res 840(1-2):138-147

67. Meerlo P, de Bruin EA, Strijkstra AM, Daan S (2001) A social conflict increases EEG slow-wave activity during subsequent sleep. Physiol Behav 73(3):331335

68. Balkaya M, Seidel JL, Sadeghian H, Qin T, Chung DY, Eikermann-Haerter K, van den Maagdenberg AMJM, Ferrari MD, Ayata C (2019) Relief following chronic stress augments spreading depolarization susceptibility in familial hemiplegic migraine mice. Neuroscience. 415:1-9

69. Böhm M, Chung DY, Gómez CA, Qin T, Takizawa T, Sadeghian H, Sugimoto K, Sakadžić S, Yaseen MA, Ayata C. Neurovascular coupling during optogenetic functional activation: Local and remote stimulus-response characteristics, and uncoupling by spreading depression. J Cereb Blood Flow Metab. 2020;40(4):808-822

70. Sotocinal SG, Sorge RE, Zaloum A, Tuttle AH, Martin $\amalg$, Wieskopf JS, Mapplebeck JC, Wei P, Zhan S, Zhang S, McDougall JJ, King OD, Mogil JS (2011) The rat grimace scale: a partially automated method for quantifying pain in the laboratory rat via facial expressions. Mol Pain 7:55

\section{Publisher's Note}

Springer Nature remains neutral with regard to jurisdictional claims in published maps and institutional affiliations.

Ready to submit your research? Choose BMC and benefit from

- fast, convenient online submission

- thorough peer review by experienced researchers in your field

- rapid publication on acceptance

- support for research data, including large and complex data types

- gold Open Access which fosters wider collaboration and increased citations

- maximum visibility for your research: over $100 \mathrm{M}$ website views per year

At BMC, research is always in progress.

Learn more biomedcentral.com/submission 